\title{
Growth restriction in gastroschisis: quantification of its severity and exploration of a placental
} cause

\author{
Nathaniel R Payne ${ }^{1,2^{*}}$, Susan C Simonton ${ }^{3}$, Sam Olsen ${ }^{4}$, Mark A Arnesen ${ }^{5}$ and Kathleen M Pfleghaar ${ }^{6}$
}

\begin{abstract}
Background: Gastroschisis patients are commonly small for gestational age (SGA, birth weight $[B W]<10^{\text {th }}$ centile). However, the extent, symmetry and causes of that growth restriction remain controversial.

Methods: We compared BW, crown-heel length (LT), occipitofrontal circumference (OFC) and ponderal index (PI) in 179 gastroschisis cases and 895 matched controls by univariate and multiple regression. Fetal ultrasounds $(\mathrm{N}=80)$ were reviewed to determine onset of growth restriction. Placental histology was examined in 31 gastroschisis patients whose placental tissue was available and in 29 controls.

Results: Gastroschisis cases weighed less than controls (BW $=2400 \pm 502 \mathrm{~g}$ vs. $2750 \pm 532 \mathrm{~g}, \mathrm{p}<0.001$ ) and their BW frequency curve was shifted to the left, indicating lower BW as a group compared to controls $(p<0.001$ by Kolmogorov-Smirnov test). BW differences varied from $-148 \mathrm{~g}$ at 33 weeks to $-616 \mathrm{~g}$ at 38 weeks gestation. Intrauterine growth restriction was symmetric with gastroschisis patients having a shorter LT (45.7 \pm 3.3 vs. $48.4 \pm$ $2.7 \mathrm{~cm}, \mathrm{p}<0.001)$, smaller OFC (31.9 \pm 1.9 vs. $32.9 \pm 1.6 \mathrm{~cm}, \mathrm{p}<0.001)$, but larger ponderal index (2.51 \pm 0.37 vs. $2.40 \pm 0.16, \mathrm{p}<0.001)$ compared to controls. Gastroschisis patients had a similar reduction in BW $(-312 \mathrm{~g}, 95 \%$ confidence interval $[\mathrm{Cl}]=-367,-258)$ compared to those with chromosomal abnormalities $(-239 \mathrm{~g}, \mathrm{Cl}=-292,-187)$. Growth deficits appeared early in the second trimester and worsened as gestation increased. Placental chorangiosis was more common in gastroschisis patients than controls, even after removing all SGA patients $(77 \%$ vs. $42 \%, p=$ 0.02).
\end{abstract}

Conclusions: Marked, relatively symmetric intrauterine growth restriction is an intrinsic part of gastroschisis. It begins early in the second trimester, and is associated with placental chorangiosis.

\section{Background}

Gastroschisis is a unique congenital anomaly appearing as a defect in the abdominal wall usually to the right of the umbilicus. It commands increasing interest because of its rising prevalence [1-4] and clinical impact $[5,6]$. Most gastroschisis cases present with an isolated anomaly, which develops around the $6^{\text {th }}$ gestational week [7] and is not usually associated with chromosomal abnormalities $[8,9]$. However, almost all studies report gastroschisis patients have an increased risk of being small for gestational age (SGA, birth weight $[\mathrm{BW}]<10^{\text {th }}$ centile) $[6,10-13]$. Previous fetal studies reported not

\footnotetext{
* Correspondence: rob.payne@childrensmn.org

'Department of Epidemiology, Michigan State University, B601 West Fee Hall, East Lansing, Michigan 48824, USA

Full list of author information is available at the end of the article
}

only a high prevalence of SGA (up to 61\%), but also a leftward shift in the BW distribution compared to intrauterine fetal growth curves [11,13]. Determining the appropriate comparison standard for gastroschisis cases may not be straightforward, since these patients' mothers have a unique demographic profile that may differ from that of the population from which the standards were developed [14-19]. Mothers of gastroschisis patients are more likely to be young, primigravida, undernourished, smokers, and tend to have a low BMI, [2,15-19] all factors that are also associated with decreased intrauterine growth [20] and which might confound any association of gastroschisis with intrauterine growth. The extent, symmetry and causes of growth restriction remain controversial. The purpose of this study was to characterize and quantitate the fetal growth

\section{Biomed Central}


restriction in gastroschisis and to explore the role of placental dysfunction as a cause of this growth deficit.

\section{Methods}

\section{Study design}

This retrospective, case-control study was a secondary analysis of data collected on all newborns admitted to the NICUs of Children's Hospitals and Clinics of Minnesota. We conducted four analyses in this study. Analysis \#1) We compared BW, crown-heel length (LT), occipitofrontal circumference (OFC), and ponderal index (PI) at birth in gastroschisis cases to that in matched controls without major congenital anomalies and to neonatal and fetal growth standards [21-24]. Analysis \#2) We examined the same measures of size at birth comparing gastroschisis patients to other groups of anomalies: a) isolated gastrointestinal (GI) anomalies other than gastroschisis, b) isolated renal anomalies, c) isolated cardiac anomalies, d) chromosomal anomalies, e) all other anomalies, and f) those with no recorded, major anomaly (Figure 1). Analysis \#3) We examined estimated fetal weight determined by prenatal ultrasound in gastroschisis patients. Analysis \#4) Finally, we examined placental findings in gastroschisis patients and controls.

\section{Subjects}

Our study population was live-born patients with gastroschisis. The study sample included all gastroschisis cases admitted to Children's Hospitals and Clinics of Minnesota either at the Minneapolis campus from 1 January 1990 to 31 December 2007 or at the St. Paul campus from 1 January 2004 to 31 December 2007 (Figure 1). We identified 179 cases of gastroschisis. There were no delivery room deaths among gastroschisis patients. Information on terminations, stillbirths, and fetal deaths was not available. The Institutional Review Boards of Children's Hospitals and Clinics of Minnesota (No. 0811-104) and Abbott Northwestern Hospital (No. 2558-1E) approved this study.

For the first analysis, we matched five controls to each case on a case-to-case basis by gestational age, gender, and multiple gestation status, using computerized random sampling of potential controls without replacement

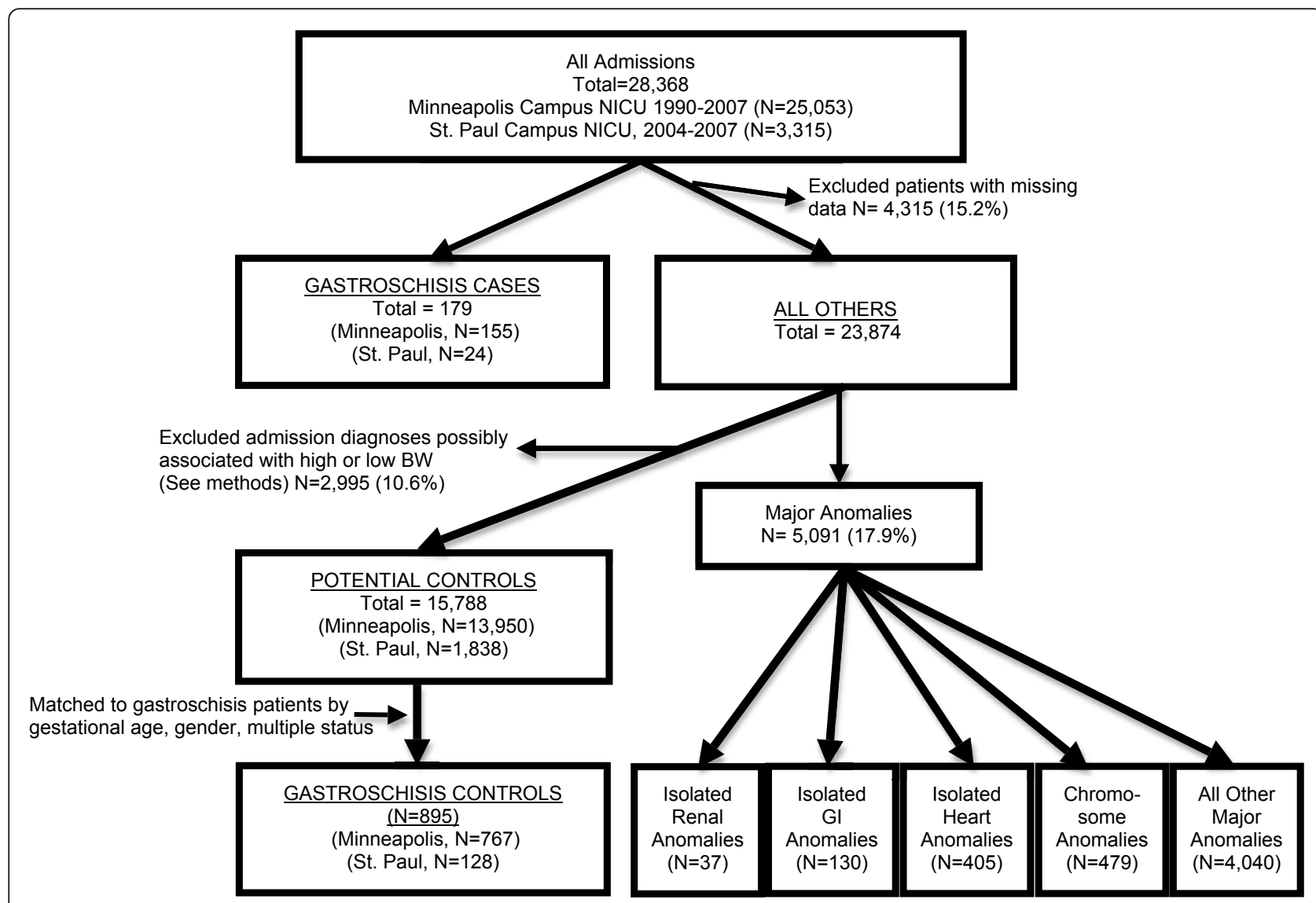

Figure 1 Flow diagram showing the total study population, exclusions, and final sample sizes. Percentages are calculated using the total number of available patients before exclusions. 
(Table 1). Since half of all gastroschisis patients are born at $\leq 36$ weeks gestation and virtually all infants with gestational age $\leq 36$ weeks gestation are admitted to a NICU, controls came from the same NICU population as cases $(\mathrm{N}=28,368$, Figure 1$)$. We excluded potential controls with missing data $(\mathrm{N}=4315,15.2 \%)$ or major anomalies $(\mathrm{N}=5091,17.9 \%)$ (Figure 1$)$. For the purposes of this study, the following recorded diagnoses and procedures represented or potentially represented major anomalies: renal malformations, congenital heart disease (excluding patent ductus arteriosus), central nervous system malformations, chromosome abnormalities, major skeletal anomalies, recognizable dysmorphic syndromes and thoracic, abdominal, head/neck, or heart surgery. No congenital infections were diagnosed in cases or controls. To minimize the risk of bias in controls' growth measures, [25,26] we included only patients with admission diagnoses unlikely to be

Table 1 Characteristics of study cases and controls

\begin{tabular}{|c|c|c|c|}
\hline Feature & Gastroschisis $(n=179)$ number $(\%)$ & Controls $(n=895)$ number $(\%)$ & $p$-value ${ }^{a}$ \\
\hline Gestational age (weeks) (mean \pm sd) & $36 \pm 2$ & $36 \pm 2$ & 1.000 \\
\hline Maternal age (years) (mean \pm sd) & $22 \pm 4$ & $30 \pm 3$ & $<0.001$ \\
\hline Age $\leq 20$ years $(\%)$ & 69 (38.6) & $44(5.0)$ & \\
\hline Age $20-24$ years $(\%)$ & $70(39.1)$ & $154(17.2)$ & \\
\hline Age $25-29$ years (\%) & $31(17.3)$ & $248(27.7)$ & \\
\hline Age $\geq 30$ years (\%) & $9(5.0)$ & $449(50.2)$ & \\
\hline Maternal race & & & $<0.001$ \\
\hline Caucasian (\%) & $140(78.2)$ & $741(82.8)$ & \\
\hline African American (\%) & $7(3.9)$ & $90(10.1)$ & \\
\hline Asian (\%) & 19 (10.6) & $38(4.3)$ & \\
\hline Hispanic (\%) & $8(4.5)$ & $20(2.2)$ & \\
\hline Native American (\%) & $5(2.8)$ & $6(0.7)$ & \\
\hline Female & $84(47.0)$ & $420(47.0)$ & 1.000 \\
\hline Inborn (\%) & $155(86.6)$ & $697(77.9)$ & 0.008 \\
\hline Birth weight $<10^{\text {th }}$ centile $^{\mathrm{b}}(\%)$ & $44(24.6)$ & $69(7.7)$ & $<0.001$ \\
\hline Gestational hypertension/pre-eclampsia (\%) & 0 & $148(16.5)$ & $N / A^{e}$ \\
\hline Single (\%) & $113(63.1)$ & $224(25.0)$ & $<0.001$ \\
\hline Minor anomalies (\%) & $24(13.4)$ & $39(4.4)$ & $<0.001$ \\
\hline Multiple gestation & $4(2.2)$ & $20(2.2)$ & 1.000 \\
\hline Primigravida & $110(61.5)$ & $285(31.8)$ & $<0.001$ \\
\hline Gestational diabetes $^{f}$ & $1(0.6)$ & $63(7.3)$ & 0.010 \\
\hline Pre-existing (before pregnancy) diabetes ${ }^{f}$ & 0 & $27(3.3)$ & $N / A^{e}$ \\
\hline Maternal smoking & $52(29.1)$ & $138(15.4)$ & $<0.001$ \\
\hline Maternal illicit drug use & $7(3.9)$ & $32(3.6)$ & 0.829 \\
\hline Maternal alcohol use & $7(3.9)$ & $16(1.8)$ & 0.082 \\
\hline Center (Minneapolis) & $155(86.6)$ & $767(85.7)$ & 0.754 \\
\hline Era (1999-2007) & $129(72.1)$ & $581(64.9)$ & 0.065 \\
\hline Birth weight (g) & $2400 \pm 502$ & $2750 \pm 532$ & $<0.001$ \\
\hline Birth weight z-score & $-0.65 \pm 0.86$ & $0.11 \pm 0.49$ & $<0.001$ \\
\hline Crown-heel length $(\mathrm{cm})$ & $45.7 \pm 3.3$ & $48.4 \pm 2.7$ & $<0.001$ \\
\hline Crown-heel length $z$-score $e^{c, d}$ & $-0.50 \pm 1.19$ & $0.68 \pm 0.55$ & $<0.001$ \\
\hline Occipitofrontal circumference (OFC) & $31.9 \pm 1.9$ & $32.9 \pm 1.6$ & $<0.001$ \\
\hline OFC z-score ${ }^{d}(\mathrm{~cm})$ & $-0.36 \pm 0.87$ & $0.24 \pm 0.45$ & $<0.001$ \\
\hline Ponderal index & $2.51 \pm 0.37$ & $2.40 \pm 0.16$ & $<0.001$ \\
\hline Ponderal index z-score & $-0.06 \pm 0.85$ & $-0.30 \pm 0.34$ & $<0.001$ \\
\hline
\end{tabular}

a Determined for continuous variables using paired t-test comparing the gastroschisis cases as individuals and the mean of the five matched controls' values as the paired control. Determined for the selected dichotomous and categorical variables using conditional logistic regression with adjustment for matching.

${ }^{\mathrm{b}}$ Small for gestational age status determined as $\mathrm{BW}<10^{\text {th }}$ centile for gestational age using the standards of Fenton, et al.[21]

' $Z$-scores calculated by method of Cole, et al.[22]

${ }^{d}$ Length and OFC were missing in two gastroschisis cases, $\mathrm{N}=177$ for paired t-tests.

e Unable to estimate $p$-value with no cases in one or more cells.

${ }^{f}$ Presence or absence of pre-existing and gestational diabetes missing for 12 cases and 11 controls. 
associated with abnormal intrauterine growth: prematurity, respiratory distress, $\mathrm{R} / \mathrm{O}$ sepsis, unstable temperature, and "observation status."

For the $2^{\text {nd }}$ analysis, we examined additional patient groups with isolated renal $(\mathrm{N}=37)$, GI anomalies other than gastroschisis $(\mathrm{N}=130)$, cardiac $(\mathrm{N}=405)$, chromosomal $(\mathrm{N}=479)$ and any other congenital anomaly $(\mathrm{N}=$ 4040, Figure 1). Isolated renal anomalies included 26 cases with hydronephrosis and 11 cases of multicystic/ polycystic kidneys. Isolated GI anomalies included imperforate anus- 52 cases, Hirschsprung's Disease- 47, and intestinal atresia- 31 . The three most commonly recorded cardiac diagnoses were d-transposition of the great arteries- 114, hypoplastic left heart syndrome- 74, and aortic coarctation- 63 cases. The three most common chromosomal anomalies were trisomy 21-225, trisomy 18 - 31, and trisomy $13-16$ cases. All remaining patients with major anomalies were included in the final group of "any other major anomaly". These four groups of major anomalies and the gastroschisis cases were compared to the 15,788 patients without major anomalies (Figure 1).

For the $3^{\text {rd }}$ analysis using prenatal ultrasound data, there were 80 women with at least one available ultrasound evaluation. For the $4^{\text {th }}$ analysis, there were 31 gastroschisis and 29 control patients with available placental tissue.

\section{Neonatal clinical data}

Data were collected concurrent with hospitalization as part of an ongoing NICU outcomes monitoring project. BW, LT, and OFC were obtained by NICU nurses and neonatal nurse practitioners. Prenatal ultrasounds were interpreted by board-certified perinatologists. Fetal weight estimates were based on the standards of Hadlock, et al [14]. A board-certified pathologist (MAA) or pediatric pathologist (SCS) reviewed placental histological findings. Placental weight was obtained after draining, trimming, and patting the placenta dry. The placental weight $\mathrm{z}$-score was calculated using published standards $[27,28]$.

\section{Clinical definitions}

Gestational age came from obstetrical estimates based on last menstrual period and corrected by early second trimester ultrasound, if available. If physical exam indicated a gestational age $>2$ weeks different from the obstetrical estimate, the estimate from the physical exam was used. Small for gestational age (SGA) was defined as $\mathrm{BW}<10^{\text {th }}$ centile [21]. Ponderal index (PI), average neonatal weight gain and fetal growth were assessed using published standards [24,28,29]. Ponderal index was defined as weight in $\mathrm{kg}$ divided by length in meters cubed [23]. Gestational hypertension and pre- eclampsia were determined by the treating obstetrician's assessment and collapsed into a single group, gestational hypertension. Maternal smoking, a dichotomous variable, was determined by the mother's report as present if the mother smoked after she knew she was pregnant.

\section{Placental analysis}

We examined the original slides of available placentas to determine the presence of abnormalities. All slides were examined by a board-certified pediatric pathologist (SCS). The diagnosis of chorangiosis, capillary proliferation in placental terminal villi, was made using the definition of Altschuler and Baergen [30,31] with slight modication as follows: 1) Focal chorangiosis was defined as $>10$ capillaries in $>10$ terminal villi in 10 fields at $10 \times$ magnification in each of $1-2$ of 3 slides. Diffuse chorangiosis was defined as $>10$ capillaries in $>10$ terminal villi in 10 fields at $10 \mathrm{X}$ magnification in each of 3 slides. Chorangiosis usually represents chronic hypoxic environment for the fetus and manifests an attempt to enlarge the placental diffusional surface [30,31].

\section{Statistical analysis}

For the $1^{\text {st }}$ analysis, we compared cases with matched controls using univariate conditional logistic regression for dichotomous and categorical variables. Continuous variables were compared by the paired t-test after averaging values for the five controls, thus consolidating the five controls' values into a single value. BW distributions of cases and controls were analyzed using the Kolmorogov-Smirnov test. We adjusted for possible covariates using multiple linear regression. We included in the regresion equation all available variables that were associated with BW by univariate analysis with a p-value < 0.10 or that might reasonably influence BW [20]. Substantial collinearity was not present (variance inflation factors, 1.02 - 1.71). Gestational age, gender, and multiple gestation accounted for $50 \%$ of the variation in BW. These variables were not included in the regression analysis because they were perfectly matched among cases and controls. The regression equation without these variables explained $10 \%$ of the variation in BW and LT, $9 \%$ of the variation in OFC and $7 \%$ in the variation of PI. Our study had $>99 \%$ power to detect a $\geq 10 \%$ difference in the mean BW of gastroschisis patients and controls at the $\mathrm{p}=0.05$ level. For analysis \#2, we also used multiple regression to compare the different groups with anomalies to the group without anomalies. We included the same covariates as above and added gender, gestational age and multiple gestation, since these data were not matched. Variance inflation factors were 1.01 - 1.13. Regression results accounted for $82 \%$, $81 \%$, $78 \%$ and $10 \%$ of the variation in BW, LT, OFC, and PI 
respectively. For analysis \#3, we used univariate descriptive statistics and sign ranks tests to compare prenatal ultrasound estimates of fetal weight and birth weight. For analysis \#4, we used the Fisher exact test to compare placental findings in cases and controls. We used only 2 -sided p-values and made no adjustment for multiple comparisons. All analyses were performed with Stata, version 11.1 (College Park, TX).

\section{Results}

\section{Patient population and demographics}

We identified 179 gastroschisis cases to whom we matched 895 controls (5:1 ratio, Figure 1$)$ with the following admission diagnoses: respiratory distress $(\mathrm{N}=$ $390)$, prematurity $(N=353)$, rule out sepsis $(N=67)$, need for observation $(\mathrm{N}=72)$, and unstable temperature $(\mathrm{N}=13)$. Mothers of gastroschisis cases were significantly younger, more commonly single, Asian, primigravid, and less likely to have gestational hypertension compared to mothers of controls (Table 1). Gastroschisis cases were more likely to be inborn, SGA and have minor anomalies (in addition to gastroschisis) compared to controls (Table 1). Examples of these relatively minor anomalies were supernumerary digit, talipes equinovarus deformity, and cyst in filum terminale. SGA was more common among gastroschisis patients across all maternal age groups (Figure 2).

\section{\#1 Analysis: Case-control comparison}

Mean BW of gastroschisis cases was 350 grams less than controls (Mean \pm standard deviation [sd]), $2400 \pm 502$

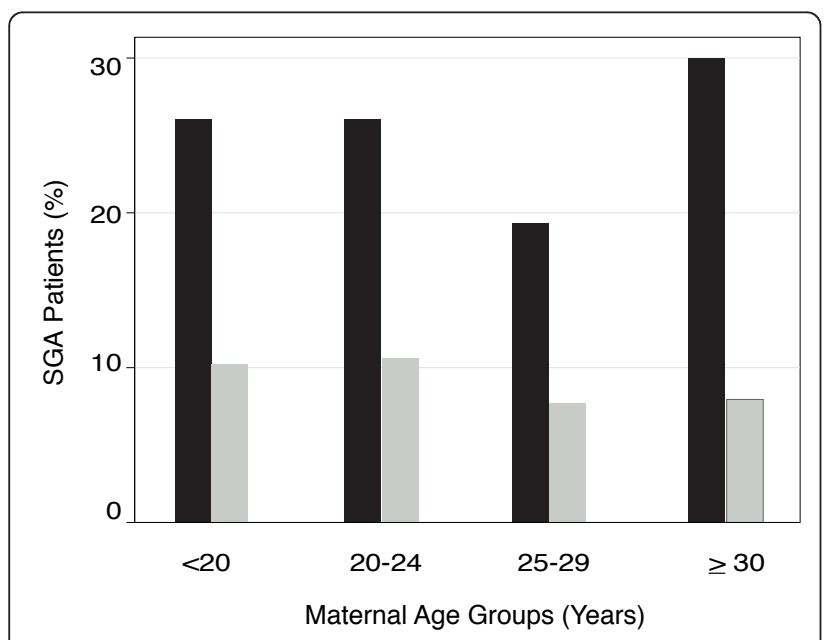

Figure 2 The percent of SGA infants (birth weight $<10^{\text {th }}$ centile) by maternal age group in gastroschisis cases (black bars) and controls (gray bars). For neither gastroschisis nor controls was the rate of SGA significantly different among the maternal age groups ( $p=0.931$ and $p=0.326$, respectively by Fisher exact test).

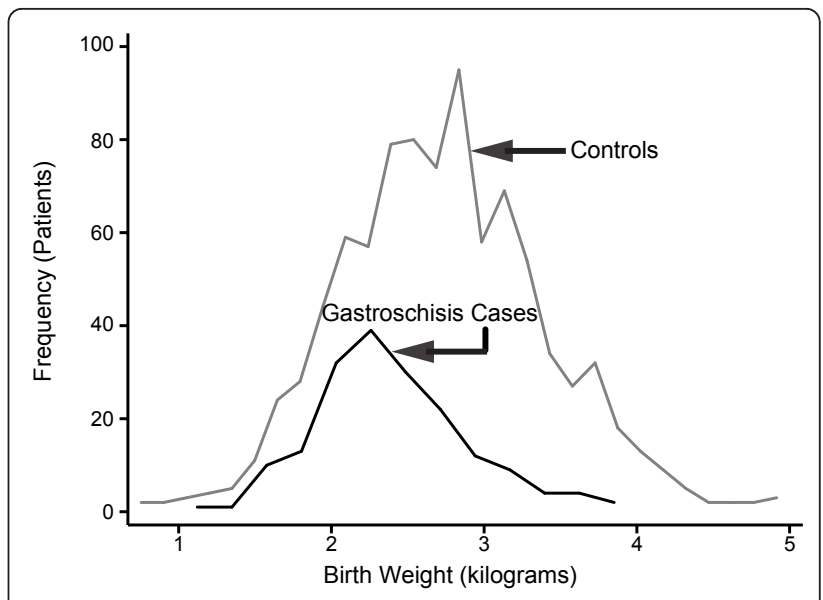

Figure 3 Frequency line graphs of the birth weight distribution of gastroschisis cases (black line) and controls (gray line) Kolmogorov-Smirnov test confirmed that this difference was significant $(p<0.001)$.

vs. $2750 \pm 532$ grams, $\mathrm{p}<0.001)$. The $\mathrm{BW}$ frequency curve for gastroschisis cases was shifted to the left compared to controls, suggesting that gastroschisis cases overall had significantly lower BW than controls (Figure 3, Kolmogorov-Smirnov test, $\mathrm{p}<0.001)$. Generalized Lorenz graphs of the cumulative mean birth weight also demonstrated this difference (Figure 4). Similarly, mean length was $2.7 \mathrm{~cm}$ shorter (LT $45.7 \pm 3.3$ vs. $48.4 \pm 2.7$ $\mathrm{cm}, \mathrm{p}<0.001)$ and mean OFC was $1.0 \mathrm{~cm}$ smaller $(31.9$ \pm 1.9 vs. $32.9 \pm 1.6 \mathrm{~cm}, \mathrm{p}<0.001$ ) than controls (Table $1)$. The PI was slightly higher than that of controls $(2.51$

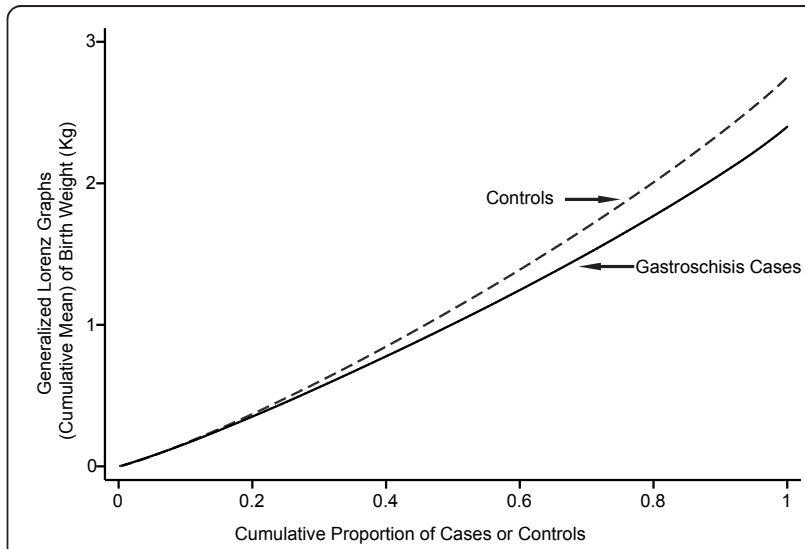

Figure 4 Generalized Lorenz graphs of the birth weight for gastroschisis cases (black line) and controls (interrupted gray line). The $X$-axis represents the proportion of the population of both cases and controls. The $Y$-axis represents the cumulative mean birth weight, calculated as cumulative birth weight at the given proportion of the population divided by the total population. These curves are a measure birth weight distribution and indicate gastroschisis cases have a lower cumulative mean birth weight at almost all proportions of the study sample. 
vs. $2.40, \mathrm{p}<0.001)$. These findings were consistent with relatively symmetric growth restriction.

Since the gastroschisis babies who were severely growth restricted, $\mathrm{BW}<10^{\text {th }}$ centile, might skew the analysis, we repeated the comparisons after eliminating the 44 SGA cases and their associated controls. Gastroschisis cases were still lighter by $199 \mathrm{~g}$ (2530 \pm 489 vs. $2729 \pm 563 \mathrm{~g}, \mathrm{p}<0.001)$, shorter by $1.9 \mathrm{~cm}(46.4 \pm 3.1$ vs. $48.3 \pm 2.8 \mathrm{~cm}, \mathrm{p}<0.001)$, and had a smaller OFC by $0.6 \mathrm{~cm}(32.2 \pm 1.9$ vs. $32.8 \pm 1.7$ cm., p < 0.001) compared to controls. Similarly, PI was again very slightly higher in cases than controls $(2.5 \pm 0.4$ vs. $2.4 \pm 0.2, \mathrm{p}<$ $0.001)$. Growth restriction occurred across the BW distribution of gastroschisis patients whether or not they met the technical definition of SGA (Figure 3).

We then adjusted for other demographic features that might confound the association of poor fetal growth and gastroschisis. Black race, Asian race, maternal hypertension, illicit drug use and nulliparity were all negatively associated with BW (Table 2). Maternal diabetes was positively associated with BW. After adjustment for potential confounders, there remained a 317 g reduction in $\mathrm{BW}(95 \% \mathrm{CI}=-415,-218, \mathrm{p}<0.001)$, a $2.5 \mathrm{~cm}$ reduction in LT (95\% CI $=-3.1,-1.9, \mathrm{p}<0.001), 0.8 \mathrm{~cm}$ reduction in OFC $(95 \% \mathrm{CI}=-1.1,-0.5)$, and a similar increase in PI of 0.1 (95\% CI $=0.03,0.17, \mathrm{p}=0.006)$ with gastroschisis compared to controls (Table 2). There was an interaction between gastroschisis and gestational age. From 33 to 38 weeks gestation, the BW difference between cases and controls increased from $-148 \mathrm{~g}$ to $-616 \mathrm{~g}$ (7\% to $18 \%$ of controls' BW, Figure 5$)$. Therefore, gastroschisis patients became progressively lighter compared to controls of the same gestational age.

Slow neonatal growth exacerbated slow intrauterine growth. Mean weight gain for gastroschisis cases was 6.5 $\mathrm{g} / \mathrm{kg} /$ day. Gastroschisis cases dropped from a mean BW z-score of $-0.65 \pm 0.86$ (31st centile) at birth to $-0.94 \pm$ 0.79 (23rd centile) at discharge. Although cross-sectional birth weight standards are not designed to measure longitudinal growth, our findings suggested that postnatal growth deficits compounded those occurring before birth in gastroschisis cases.

\section{\#2 Analysis: Comparison of gastroschisis and other patients with anomalies}

We then examined intrauterine growth restriction in gastroschisis cases compared to other patients with major anomalies (Table 3). Gastroschisis, chromosomal anomalies and isolated congenital heart disease were all associated with significantly lower BW when compared

Table 2 Unadjusted and adjusted analysis of birth weight among gastroschisis patients and Controls

\begin{tabular}{|c|c|c|c|c|c|c|}
\hline & \multicolumn{3}{|c|}{ Unadjusted } & \multicolumn{3}{|c|}{ Adjusted } \\
\hline & Coefficient $^{a}$ & $95 \% \mathrm{Cl}^{\mathrm{b}}$ & p-value & Coefficient $^{c}$ & $95 \% \mathrm{Cl}^{\mathrm{b}}$ & p-value \\
\hline Gastroschisis & -350 & $-415,-286$ & $<0.001$ & -317 & $-415,-218$ & $<0.001$ \\
\hline Gestational age (weeks) & 228 & 213,244 & $<0.001$ & $N D^{c}$ & ND & ND \\
\hline Male gender & 107 & $-39,253$ & 0.151 & $N^{c}$ & ND & ND \\
\hline Multiple gestation & -241 & $-391,-92$ & 0.002 & $N^{c}$ & ND & ND \\
\hline \multicolumn{7}{|l|}{ Maternal race/ethnicity } \\
\hline White & Referent & & & Referent & & \\
\hline African American & -250 & $-363,-136$ & $<0.001$ & -236 & $-368,-104$ & 0.001 \\
\hline Native American & 1 & $-429,431$ & 0.996 & 277 & $-181,735$ & 0.235 \\
\hline Asian & -219 & $-344,-95$ & 0.001 & -178 & $-301,-55$ & 0.005 \\
\hline Hispanic & -182 & $-480,115$ & 0.229 & -178 & $-510,155$ & 0.292 \\
\hline Gestational diabetes & 134 & $-53,323$ & 0.160 & 77 & $-106,260$ & 0.407 \\
\hline Pre-existing diabetes & 628 & 348,908 & $<0.001$ & 689 & 406,973 & $<0.001$ \\
\hline Maternal smoking & -220 & $-313,-128$ & $<0.001$ & -142 & $-249,-34$ & 0.010 \\
\hline Maternal hypertension & -251 & $-372,-129$ & $<0.001$ & -354 & $-473,-234$ & $<0.001$ \\
\hline Maternal illicit drug use & -378 & $-545,-211$ & $<0.001$ & -255 & $-453,-58$ & 0.012 \\
\hline Maternal alcohol use & -390 & $-603,-176$ & 0.005 & -143 & $-358,71$ & 0.189 \\
\hline Single mother & -234 & $-316,-152$ & $<0.001$ & -59 & $-161,42$ & 0.250 \\
\hline Maternal age (years) & 13 & 7,18 & $<0.001$ & -2 & $-9,6$ & 0.654 \\
\hline Nullipara & -164 & $-246,-82$ & $<0.001$ & -98 & $-192,-6$ & 0.037 \\
\hline Outborn (yes $=1$, no $=0$ ) & 239 & 141,337 & $<0.001$ & 136 & 42,230 & 0.005 \\
\hline Era (1999-2007) & 1 & $-72,74$ & 0.980 & 27 & $-44,98$ & 0.452 \\
\hline
\end{tabular}

${ }^{a}$ Obtained by univariate regression

${ }^{\mathrm{b}} \mathrm{Cl}=95 \%$ confidence interval

c Adjusted coefficient obtained by multiple regression. Since cases and controls were perfectly matched for gestational age, gender, and multiple gestation, these variables were not included in the multiple regression analyses. All other potential covariates were included (see methods). 


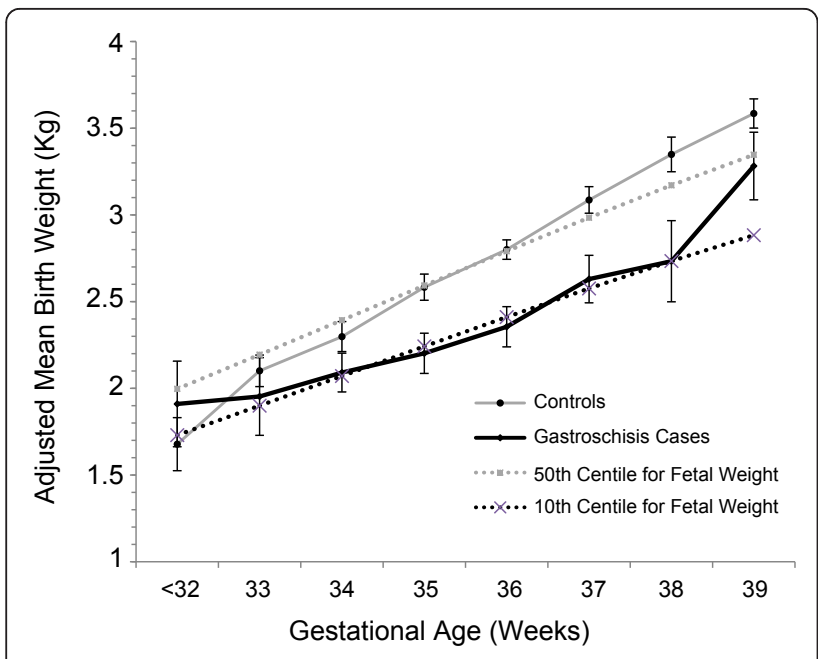

Figure 5 Adjusted mean BW of gastroschisis cases (black line) and controls (gray line) by gestational age with the $95 \%$ confidence intervals represented by the error bars. The $10^{\text {th }}$ and $50^{\text {th }}$ centiles were obtained from published standards[24]. BW was adjusted using the regression equation from Table 2 and included maternal race, cigarette smoking, GHP, recreational drug use, previous pregnancies and inborn status. From 33 weeks to about 38 weeks gestation, gastroschisis cases weighed progressively less than controls, changing from -148 grams to -616 grams. The percentage of BW deficit in gastroschisis cases increased from $7 \%$ at 33 weeks gestation to $18 \%$ at 38 weeks. The small number of patients available for analysis prior to 33 and after 38 weeks resulted in wide confidence intervals and potentially unreliable estimates.

to those without major anomalies. After adjusting for covariates by multiple regression analysis, gastroschisis was associated with a $312 \mathrm{~g}$ (CI 368, 259; p < 0.001) reduction in $\mathrm{BW}$ compared to infants with no major anomalies. The BW reduction associated with gastroschisis was somewhat larger than that seen with chromosomal anomalies (234-g reduction, CI -285, -182; p < 0.001 grams). LT and OFC showed similar differences before (Table 3) and after adjustment for covariates (data not shown). Gastroschisis was unique among the groups of anomalies that we examined in causing severe growth restriction, similar in degree to that seen with chromosomal abnormalities.

\section{\#3 Analysis: Onset of decreased intrauterine growth}

We reviewed the prenatal ultrasounds of 80 women pregnant with a baby with gastroschisis. Their first ultrasound was obtained at a median of 26 weeks (range 21 - 38) gestation. At the first ultrasound, almost all gastroschisis patients had a low estimated fetal weight (median estimated fetal weight centile $=27$, range 3 70). Among those with more than one fetal ultrasound, $32 / 54$ (59\%) had either a drop or no change in estimated fetal weight centile between the first and last fetal weight estimate. The mean $( \pm \mathrm{sd})$ time between the first and last fetal ultrasound was $9 \pm 3$ weeks. Fetal growth restriction appeared by at least the second trimester and generally worsened as gestation advanced.

We then compared estimated fetal weight percentile and birth weight percentile in the 61 women who had an ultrasound within 3 weeks of delivery (Table 4). Estimated fetal weight was lower than actual birth weight, but this was probably attributable to the interval between the last ultrasound measurement and delivery. Estimated fetal weight percentile and measured birth weight percentile did not differ (Table 4).

\section{\#4 Analysis: Placental abnormalities associated with gastrochisis cases}

We examined the placental weight, placental weight zscores and histology in the 31 available placentas from gastroschisis cases and from 29 controls. There was no significant relationship between placental wt z-score and $\mathrm{BW} z$-score $(\mathrm{R}=0.204, \mathrm{p}=0.063)$. However, placentas of gastroschisis cases had a significantly higher prevalence of chorangiosis ( $81 \%$ vs. $41 \%, \mathrm{p}=0.003$ ) and villous edema $(33 \%$ vs. $0 \%, p=0.005)$, but not chorioamnionitis ( $42 \%$ vs. $48 \%, \mathrm{p}=0.796$, Table 5 ). Even after removing SGA patients (chorangiosis is associated with SGA), placentas from gastroschisis patients still had chorangiosis more frequently than controls (77\% vs. $42 \%, \mathrm{p}=0.02$ ). Representative photomicrographs of chorangiosis in the placenta associated with a gastroschisis case and no chorangiosis in a control appear in Figures 6 and 7, respectively. Among patients with chorangiosis, only one (a gastroschisis case) infant's mother had diabetes, a condition also known to be associated with chorangiosis. No other significant findings were seen, such as infarcts or fibrinoid deposition.

\section{Discussion}

Our study further characterizes the association of poor fetal weight gain and gastroschisis that has been reported by others [5,6,10-13,32-34]. Intrauterine growth restriction of some degree often accompanies gastroschisis, even when the BW percentile is $>10^{\text {th }}$ percentile [11]. In many cases, the degree of growth restriction is marked. The adjusted mean growth deficit with gastroschisis was $317 \mathrm{~g}$. This growth deficit could not be explained by maternal factors, which might be common to mothers delivering a baby with either gastroschisis or with growth restriction associated with another condition $[17,18]$. Our limited prenatal ultrasound data suggested that growth restriction began early in the second trimester and worsened with increasing gestation. This is consistent with others' observations [10-13]. Taken together our data confirm that intrauterine growth restriction is a near universal finding with a gastroschisis defect. 
Table 3 Birth weight, length, and occipitofrontal circumference among NICU admissions with and without anomalies

\begin{tabular}{|c|c|c|c|c|c|c|c|}
\hline & $\begin{array}{l}\text { Gastroschisis } \\
\text { (N = 179) }\end{array}$ & $\begin{array}{c}\text { No major } \\
\text { anomaly } \\
(\mathrm{N}=15,788)\end{array}$ & $\begin{array}{c}\text { Renal } \\
\text { anomalies } \\
(\mathrm{N}=37)\end{array}$ & $\begin{array}{l}\text { Other GI } \\
\text { anomalies } \\
(\mathrm{N}=130)\end{array}$ & $\begin{array}{c}\text { Chromosome } \\
\text { abnormalities } \\
(\mathrm{N}=479)\end{array}$ & $\begin{array}{c}\text { Congenital heart } \\
\text { disease }(\mathrm{N}= \\
405)\end{array}$ & $\begin{array}{l}\text { Any other major } \\
\text { anomalies } \\
(\mathrm{N}=4,040)\end{array}$ \\
\hline $\begin{array}{l}\text { Gestational } \\
\text { age (wks) }\end{array}$ & $35.7 \pm 2.0$ & $34.2 \pm 4.0$ & $34.1 \pm 5.1$ & $38.3 \pm 2.7$ & $36.5 \pm 3.3$ & $38.5 \pm 2.2$ & $33.7 \pm 5.7$ \\
\hline $\begin{array}{l}\text { Unadjusted } \\
\text { BW (g) }\end{array}$ & $2400 \pm 502$ & $2387 \pm 918$ & $2500 \pm 1.140$ & $3296 \pm 701$ & $2660 \pm 861$ & $3216 \pm 638$ & $2331 \pm 118$ \\
\hline BW z-score & $-0.64 \pm 0.86$ & $0.01 \pm 0.93$ & $0.25 \pm 1.00$ & $0.13 \pm 0.96$ & $-0.44 \pm 1.3$ & $-0.11 \pm 0.98$ & $-0.04 \pm 1.14$ \\
\hline $\begin{array}{l}\text { BW } \\
\text { coefficient }^{\mathrm{a}}\end{array}$ & $-310(-366,-254)^{b}$ & Referent & $45(-93,184)$ & $26(-55,107)$ & $-244(-298,-192)^{b}$ & $-94(-141,-47)^{b}$ & $-7(-23,10)$ \\
\hline $\begin{array}{l}\text { Unadjusted } \\
\text { LT (cm) }\end{array}$ & $45.7 \pm 3.3$ & $46.0 \pm 5.7$ & $44.8 \pm 6.8$ & $50.6 \pm 3.6$ & $46.7 \pm 5.3$ & $50.4 \pm 3.7$ & $44.3 \pm 8.1$ \\
\hline LT z-score & $-0.50 \pm 1.19$ & $0.42 \pm 1.15$ & $0.05 \pm 1.69$ & $0.57 \pm 1.04$ & $-0.37 \pm 1.53$ & $0.37 \pm 1.24$ & $0.11 \pm 1.41$ \\
\hline $\begin{array}{l}\text { LT } \\
\text { coefficient }^{\mathrm{a}}\end{array}$ & $-2.1(-2.5,-1.7)^{b}$ & Referent & $-1.3(-2.6,-0.1)^{d}$ & $-0.7(-1.1,-0.2)^{c}$ & $-2.3(-2.7,-2.0)^{b}$ & $-1.2(-1.5,-0.9)^{b}$ & $-1.1(-1.2,-1.0)^{c}$ \\
\hline $\begin{array}{l}\text { Unadjusted } \\
\text { OFC (cm) }\end{array}$ & $31.9 \pm 1.9$ & $31.5 \pm 3.5$ & $31.0 \pm 4.4$ & $34.2 \pm 2.3$ & $31.9 \pm 3.1$ & $33.9 \pm 1.9$ & $30.7 \pm 5.3$ \\
\hline OFC z-score & $-0.36 \pm 0.86$ & $0.16 \pm 1.02$ & $0.04 \pm 1.01$ & $0.04 \pm 0.97$ & $-0.56 \pm 1.30$ & $-0.24 \pm 0.95$ & $0.15 \pm 1.52$ \\
\hline $\begin{array}{l}\text { OFC } \\
\text { coefficient }^{a}\end{array}$ & $-0.5(-0.8,-0.3)^{b}$ & referent & $-0.6(-1.1,0.1)^{d}$ & $-0.6(-0.8,-0.3)^{b}$ & $-1.3(-1.5,-1.2)^{b}$ & $-1.0(-1.2,-0.9)^{b}$ & $-0.3(-0.4,-0.2)^{b}$ \\
\hline $\begin{array}{l}\text { Ponderal } \\
\text { index }\end{array}$ & $2.5 \pm 0.37$ & $2.3 \pm 0.48$ & $2.6 \pm 0.89$ & $2.5 \pm 0.33$ & $2.5 \pm 0.49$ & $2.5 \pm 0.34$ & $2.4 \pm 0.53$ \\
\hline PI z-score & $-0.06 \pm 0.85$ & $-0.24 \pm 0.91$ & $0.32 \pm 1.86$ & $-0.25 \pm 0.53$ & $-0.02 \pm 1.18$ & $-0.24 \pm 0.59$ & $-0.02 \pm 1.17$ \\
\hline $\begin{array}{l}\text { PI } \\
\text { coefficient }^{a}\end{array}$ & $0.10(0.04,0.15)^{b}$ & referent & $0.27(0.00,0.53)^{d}$ & $0.01(-0.04,0.03)$ & $0.10(0.05,0.15)^{b}$ & $-0.01(-0.04,0.03)$ & $0.08(0.06,0.10)^{b}$ \\
\hline
\end{tabular}

${ }^{a}$ Determined using covariates gestational age, gender, multiple gestation status, maternal race, maternal cigarette smoking, GHP, pre-existing and gestational diabetes, maternal illicit drug use, previous pregnancies, and inborn status. The regression model explained $82 \%$ of the variation in birth weight $\left(\mathrm{R}^{2}=0.818\right), 81 \%$ of the variation in $L T\left(R^{2}=0.810\right), 78 \%$ of the variation in OFC $\left(R^{2}=0.777\right)$ and $10 \%$ of the variation of PI $\left(R^{2}=0.103\right)$.

${ }^{b} p<0.001$

${ }^{c} p<0.01$

${ }^{d} p<0.05$

The degree of intrauterine growth restriction was actually greater than that seen with chromosomal anomalies. The ponderal index was very slightly increased, consistent with a reduction in length that was proportional to the reduction in weight. The relatively symmetrical nature of the growth restriction probably reflects early onset [35]. Compounding intrauterine growth deficits, GI dysfunction contributes to suboptimal nutrition after birth in the neonatal period $[5,6,36]$.

Our findings imply that gastroschisis patients, because of their marked intrauterine growth restriction, are at increased risk for cardiovascular disease, adult-onset diabetes, and perhaps most importantly, intellectual disability $[37,38]$. Leonard, et al., found that growth restriction increased the odds of intellectual disability by about $71 \%$ in a large Australian cohort [38]. Most gastroschisis patients are born in the late preterm period (mean gestational age at birth $=36$ weeks). Late preterm birth has also been associated with adverse cognitive and socioemotional outcomes [39]. Gastroschisis patients warrant close monitoring for developmental and intellectual problems throughout childhood [40,41].

Our study extends pathogenetic considerations to include the placenta. Placental histology suggested that placental dysfunction may contribute to growth restriction. Chorangiosis and severe villous edema were more common in gastroschisis patients than in controls. Chorangiosis is an increase in vascular channels in the terminal villi of the placenta. It is thought to represent fetal hypoxemia and the placenta's attempt to improve

Table 4 Comparison of Estimated Fetal Weight by Ultrasound and Measured Birth Weight

\begin{tabular}{lccc}
\hline & Last ultrasound measurement $(\mathbf{N}=\mathbf{6 1})^{\mathbf{a}}$ & ${\text { Measurement at birth }(\mathbf{N}=\mathbf{6 1})^{\mathbf{a}}} \mathbf{p}^{\mathbf{a}} \mathbf{v a l u e ^ { \mathbf { b } }}$ \\
\hline Weight (grams) median $(\mathrm{IQR})$ & $1956(1607-2273)$ & $2300(2050-2660)$ & $<0.001$ \\
Weight percentile median (IQR) & $27(8-38)$ & $28(10-42)$ & 0.221 \\
Gestational age (weeks) Median (IQR) & $34(33-36)$ & $36(34-37)$ & $<0.001$ \\
\hline
\end{tabular}

\footnotetext{
a There were 61 women who had an ultrasound exam at $\leq 3$ weeks before delivery

${ }^{b}$ P-value determined by signed-rank test. The data were skewed and therefore non-parametric tests were used for this small data set.

c Interquartile range.
} 
Table 5 Placental findings associated with gastroschisis

\begin{tabular}{cccc}
\hline Placental findings & Controls $\mathbf{N}=\mathbf{2 9}$ & Gastroschisis N = 31 & p-value \\
\hline Placental weight z-score (mean $\pm \mathrm{sd})^{\mathrm{a}}$ & $0.24 \pm 1.29$ & $-0.03 \pm 1.07$ & $0.804^{\mathrm{b}}$ \\
Chorioamnionitis (\%) $^{\mathrm{a}}$ & $14(48)$ & $13(42)$ & $0.796^{\mathrm{c}}$ \\
Any chorangiosis (\%) $^{\mathrm{d}}$ & $12(41)$ & $25(81)$ & $0.003^{\mathrm{c}}$ \\
Focal chorangiosis (\%) $^{\mathrm{d}}$ & $8(28)$ & $12(39)$ & $0.419^{\mathrm{c}}$ \\
Diffuse chorangiosis (\%) & $4(14)$ & $13(42)$ & $0.022^{\mathrm{c}}$ \\
\hline
\end{tabular}

\footnotetext{
${ }^{a}$ Excludes the placentas of patients who were SGA $(n=9)$, had hydrops $(n=5)$, or both $(n=3)$.

b Rank-sum test

c Fisher exact test

${ }^{d}$ Focal chorangiosis was defined as $\geq 10$ capillaries in $\geq 10$ terminal villi in 10 fields at $10 \times$ magnification in each of $1-2$ areas (slides).

e Diffuse chorangiosis was defined as $\geq 10$ capillaries in $\geq 10$ terminal villi in 10 fields at $10 \times$ magnification in each of 3 areas (slides).
}

gas exchange across the terminal villi [31] and takes weeks to develop. It has been associated with delivery at high altitude, severe maternal anemia, and diabetes mellitus [31,32]. Villous edema also suggested placental dysfunction. In a separate study, we found evidence that gestational hypertension is less common in the mothers of gastroschisis patients [42]. The placenta plays a central role in the development of gestational hypertension [43]. It is unclear how the development of gastroschisis in the fetus might be associated with decreased gestational hypertension in the mother. The placenta is often small in cases of gestational hypertension associated with fetal growth restriction [43]. However, we did not find a significant difference in the placental weight $\mathrm{z}$ score between gastroschisis patients and controls. Stoll, et al. also reported that placental size was not reduced in a smaller series of gastroschisis cases [44]. These findings, if confirmed, suggest that the placenta may

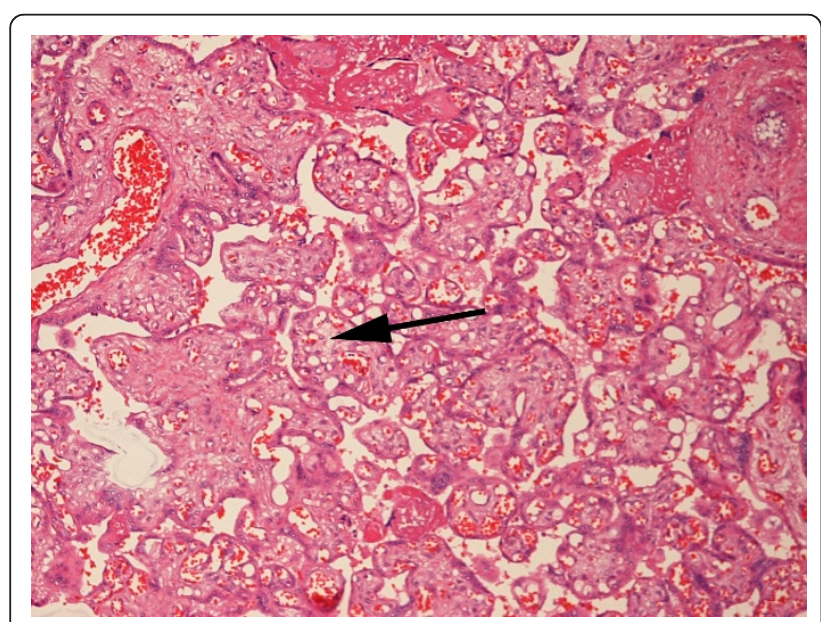

Figure 6 Figure 6. A 10x photomicrograph of chorangiosis in a placenta from a woman who delivered a patient with gastroschisis. The arrow points to an area with multiple vascular channels. Diffuse chorangiosis was defined as $\geq 10$ capillaries in $\geq$ 10 terminal villi in 10 fields at 10x magnification in each of 3 areas (slides). Red blood cells can be seen in many of the capillaries. Capillary proliferation can be seen in numerous terminal villi. develop abnormally and lead to growth restriction in gastroschisis cases, but not in the manner seen with gestational hypertension.

The exact mechanism by which growth restriction occurs in gastroschisis cases is not known. Carroll, et al. reproted diminished cord serum protein and elevated amniotic fluid protein in the amniotic fluid compared to omphalocele patients and controls [45]. Unfortunately, the patients and controls were not well matched with respect to gestational age, which could have affected the results. Protein loss through exudation of proteinaceous fluid from the intestine, which is often inflamed and exposed to the amniotic fluid throughout gestation, might well contribute to poor intrauterine growth, but probably would not account for chorangiosis. Chorangiosis provided indirect evidence of poor oxygen transfer from the placenta to the fetus. The presence of intestinal obstruction or dysfunction did not likely contribute to fetal growth restriction, since other GI anomalies, most of which were atresias, were not associated with decreased birth weight. It is possible that multiple

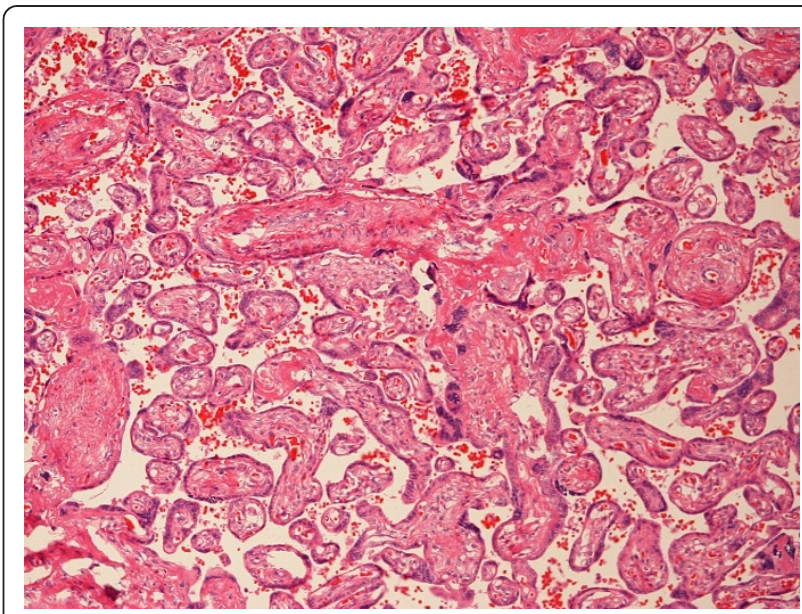

Figure 7 Figure 7. A 10x photomicrograph of a placenta from a woman who delivered a control patient. Chorangiosis is not present in this photmicrograph. 
mechanisms contribute to poor fetal growth in the presence of gastroschisis.

Several limitations should be considered when interpreting our study. All cases were referred and do not represent population-based data. However, the demographic findings of our patients are similar to previous reports [2-6]. Another concern might be error in physical measurements obtained by clinical personnel. BW of gastroschisis patients could have been biased upward due to bowel edema or the bandages used to protect exposed intestine. However, nurses routinely weigh and subtract the weight of bandages when recording $\mathrm{BW}$. Even if present, this bias would have reduced the observed BW difference between cases and controls and cannot explain our findings. Furthermore, measurements of LT and OFC, were also low and not as likely to have been influenced by the presence of gastroschisis. We were limited in the number of prenatal ultrasounds available for study. Patients were often evaluated and received their prenatal ultrasounds at satellite clinics. Only when patients received their prenatal ultrasound at the main perinatal center were the ultrasound data available to us. The strengths of this study are the large numbers of patients examined, the multiple approaches to quantifying the growth deficit and our examination of placental findings.

\section{Conclusion}

We report that relatively symmetric, intrauterine growth restriction occurs in almost all gastroschisis patients to some degree. These growth deficits are comparable to those seen in chromosomal disorders and are associated with decreased length and head circumference. Growth deficits increased from early in the second trimester until delivery, and in many cases continued through neonatal period. We found chorangiosis, a response to tissue hypoxia, to be more common in gastroschisis patients than in controls, which may implicate a placental contribution to growth restriction.

\footnotetext{
Abbreviations

BW: birth weight; Gl: gastrointestinal; g: grams; LT: crown-heel length; NICU: newborn intensive care unit; OFC: occipitofrontal circumference; PI: ponderal index; sd: standard deviation; SGA: small for gestational age

\begin{abstract}
Acknowledgements
The authors express appreciation to the NICU nurses, nurse practitioners, and NICU data managers for collecting and recording patient data, to Dr. Nigel Paneth for helpful suggestions during the study and to the neonatologists of the Children's Hospitals and Clinics of Minnesota for allowing inclusion of their patients. Dr. Cristina Pacheco kindly assisted with the photomicrographs. Dr. Payne was supported by Perinatal Epidemiology Training Grant, 5 T32 HD046377 to Michigan State University.
\end{abstract}

\section{Author details}

'Department of Epidemiology, Michigan State University, B601 West Fee Hall, East Lansing, Michigan 48824, USA. ${ }^{2}$ Department of Quality and Safety,
Children's Hospitals and Clinics of Minnesota, 2525 Chicago Avenue South, Minneapolis, MN 55404, USA. ${ }^{3}$ Department of Pathology, Children's Hospitals and Clinics of Minnesota, 2525 Chicago Avenue South, Minneapolis, MN

55404, USA. ${ }^{4}$ Department of Neonatology, Children's Hospitals and Clinics of Minnesota, 2525 Chicago Avenue South, Minneapolis, MN 55404, USA.

${ }^{5}$ Department of Pathology, Abbott Northwestern Hospital, Minneapolis, MN 55407, USA. ${ }^{6}$ Department of Perinatology, Abbott Northwestern Hospital, Minneapolis, MN 55407, USA.

\section{Authors' contributions}

NRP conceived, planned and organized the study. He also wrote the manuscript. SCS reviewed all of the placental slides. SO collected, collated and partially analyzed clinical data. MAA made available and reveiwed placental slides. KMP made available all prenatal ultrasound data and participated in the analysis of the ultrasound data. All authors reviewed the manuscript and approved its content.

\section{Competing interests}

The authors declare that they have no competing interests.

Received: 13 January 2011 Accepted: 17 October 2011

Published: 17 October 2011

\section{References}

1. Alvarez SM, Burd RS: Increasing prevalence of gastroschisis repairs in the United States: 1996-2003. J Pediatr Surg 2007, 42:943-946.

2. Vu LT, Nobuhara KK, Laurent C, Shaw GM: Increasing prevalence of gastroschisis: population-based study in California. J Pediatr 2008, 152:807-811.

3. Kilby MD: The incidence of gastroschisis. BMJ 2006, 332:250-251.

4. Mastroiacovo P, Lisi A, Castilla EE: The incidence of gastroschisis: research urgently needs resources. BMJ 2006, 332:423-424.

5. Molik KA, Gingalewski CA, West KW, Rescorla FJ, Scherer LR, Engum SA, Grosfeld JL: Gastroschisis: a plea for risk categorization. J Pediatr Surg 2001, 36:51-55.

6. Payne NR, Pfleghaar KM, Assel B, Johnson A, Rich RH: Predicting the outcome of newborns with gastroschisis. J Pediatr Surg 2009, 44:918-923.

7. Feldkamp ML, Carey JC, Sadler TW: Development of gastroschisis: review of hypotheses, a novel hypothesis, and implications for research. Am J Med Genet A 2007, 143:639-652.

8. Mastroiacovo P, Lisi A, Castilla EE, Martinez-Frias ML, Bermejo E, Marengo L, Kucik J, Siffel C, Halliday J, Gatt M, Anneren G, Bianchi F, Canessa MA, Danderfer R, de Walle H, Harris J, Li Z, Lowry RB, McDonell R, Merlob P, Metneki J, Mutchinick O, Robert-Gnansia E, Scarano G, Sipek A, Potzsch S, Szabova E, Yevtushok L: Gastroschisis and associated defects: an international study. Am J Med Genet A 2007, 143:660-671.

9. Stoll C, Alembik Y, Dott B, Roth MP: Omphalocele and gastroschisis and associated malformations. Am J Med Genet A 2008, 146A:1280-1285.

10. Brantberg A, Blaas HG, Salvesen KA, Haugen SE, Eik-Nes SH: Surveillance and outcome of fetuses with gastroschisis. Ultrasound Obstet Gynecol 2004, 23:4-13.

11. Netta DA, Wilson RD, Visintainer P, Johnson MP, Hedrick HL, Flake AW, Adzick NS: Gastroschisis: Growth patterns and a proposed prenatal surveillance protocol. Fetal Diagn Ther 2007, 22:352-357.

12. Raynor BD, Richards D: Growth retardation in fetuses with gastroschisis. J Ultrasound Med 1997, 16:13-16.

13. Horton AL, Powell MS, Wolfe HM: Intrauterine growth patterns in fetal gastroschisis. Am J Perinatol 2010, 27:211-217.

14. Hadlock FP, Harrist RB, Sharman RS, Deter RL, Park SK: Estimation of fetal weight with the use of head, body, and femur measurements-a prospective study. Am J Obstet Gynecol 1985, 151:333-337.

15. Torfs CP, Velie EM, Oechsli FW, Bateson TF, Curry CJ: A population-based study of gastroschisis: demographic, pregnancy, and lifestyle risk factors. Teratology 1994, 50:44-53.

16. Torfs CP, Lam PK, Schaffer DM, Brand RJ: Association between mothers' nutrient intake and their offspring's risk of gastroschisis. Teratology 1998, 58:241-250.

17. Lam PK, Torfs CP: Interaction between maternal smoking and malnutrition in infant risk of gastroschisis. Birth Defects Res 2006 76:182-186. 
18. Lam PK, Torfs CP, Brand RJ: A low pregnancy body mass index is a risk factor for an offspring with gastroschisis. Epidemiology 1999, 10:717-721.

19. Siega-Riz AM, Herring AH, Olshan AF, Smith J, Moore C: The joint effects of maternal prepregnancy body mass index and age on the risk of gastroschisis. Paediatr Perinat Epidemiol 2009, 23:51-57.

20. Saenger P, Czernichow P, Hughes I, Reiter EO: Small for gestational age: short stature and beyond. Endocr Rev 2007, 28:219-251.

21. Fenton T, Sauve R: Using the LMS method to calculate z-scores for the Fenton preterm infant growth chart. Eur J Clin Nutr 2007, 61:1380-1385.

22. Cole TJ: The LMS method for constructing normalized growth standards. Eur J Clin Nutr 1990, 44:45-60.

23. Rorhrer R: Der Index der Körperfülle als Mass des Ernährungszustandes. Münch Med Wochensch 1921, 68:580-588.

24. Johnsen SL, Rasmussen S, Wilsgaard T, Sollien R, Kiserud T: Longitudinal reference ranges for estimated fetal weight. Acta Obstet Gynecol Scand 2006, 85:286-297.

25. Berkson J: Limitations of the application of fourfold table analysis to hospital data. Biometrics 1946, 2:47-53.

26. Feinstein AR, Walter SD, Horwitz Rl: An analysis of Berkson's bias in casecontrol studies. J Chronic Dis 1986, 39:495-504.

27. Kraus FT, Redline WR, Gersell DJ, Nelson DM, Dicke JM: Placental Pathology Washington, DC: American Registry of Pathology; 2004

28. Dombrowski MP, Berry SM, Hurd WW, Johnson MP, Saleh AA, Sokol RJ: A gestational-age-independent model of birth weight based on placental size. Biol Neonate 1994, 66:56-64.

29. Patel AL, Engstrom JL, Meier PP, Kimura RE: Accuracy of methods for calculating postnatal growth velocity for extremely low birth weight infants. Pediatrics 2005, 116:1466-1473.

30. Altshuler G: Chorangiosis: an important placental sign of neonatal morbidity and mortality. Arch Pathol Lab Med 1984, 108:71-74.

31. Baergen RN: Manual of Benirschke and Kaufman's Pathology of the Human Placenta New York, Springer Press; 2005, 358-361.

32. David AL, Tan A, Curry J: Gastroschisis: sonographic diagnosis, associations, management and outcome. Prenat Diagn 2008, 28(7):633-644

33. Nicholas SS, Stamilio DM, Dicke JM, Gray DL, Macones GA, Odibo AO: Predicting adverse neonatal outcomes in fetuses with abdominal wall defects using prenatal risk factors. Am J Obstet Gynecol 2009, 201(4):383 e381-386.

34. Puligandla PS, Janvier A, Flageole H, Bouchard S, Mok E, Laberge JM: The significance of intrauterine growth restriction is different from prematurity for the outcome of infants with gastroschisis. J Pediatr Surg 2004, 39(8):1200-1204

35. Kramer MS, McLean FH, Olivier M, Willis DM, Usher RH: Body proportionality and head and length 'sparing' in growth-retarded neonates: a critical reappraisal. Pediatrics 1989, 84:717-723.

36. Davis RP, Treadwell MC, Drongowski RA, Teitelbaum DH, Mychaliska GB: Risk stratification in gastroschisis: can prenatal evaluation or early postnatal factors predict outcome? Pediatr Surg Int 2009, 25(4):319-325.

37. Barker DJ, Gluckman PD, Godfrey KM, Harding JE, Owens JA, Robinson JS: Fetal nutrition and cardiovascular disease in adult life. Lancet 1993, 341(8850):938-941, (1993).

38. Leonard H, Nassar N, Bourke J, Blair E, Mulroy S, de Klerk N, Bower C: Relation between intrauterine growth and subsequent intellectual disability in a ten-year population cohort of children in Western Australia. Am J Epidemiol 2007, 167:103-111.

39. Talge NM, Holzman C, Wang J, Lucia V, Gardiner J, Breslau N: Late-preterm birth and its association with cognitive and socio-emotional outcomes at 6 years of age. Pediatrics 2010, 126:1124-1131.

40. South AP, Marshall DD, Bose CL, Laughon MM: Growth and neurodevelopment at 16 to 24 months of age for infants born with gastroschisis. J Perinatol 2008, 28:702-706

41. Payne NR, Gilmore L, Svobodny S, Perdue NR, Hoekstra RE, Olsen S, Moore JR: A cross-sectional, case-control follow-up of infants with gastroschisis. J Neonatal Perinatal Med 2010, 3:207-215.

42. Payne NR, Pfleghaar KM, Blauer C, Finkelstein M, Olsen S: The inverse association between gastroschisis and gestational hypertension. $J$ Neonatal Perinatal Med 2011, 4:1-10.

43. Vinnars MT, Wijnaendts LC, Westgren M, Bolte AC, Papadogiannakis N, Nasiell J: Severe preeclampsia with and without HELLP differ with regard to placental pathology. Hypertension 2008, 51(5):1295-1299.
44. Stoll C, Alembik Y, Dott B, Roth MP: Study of placentas of children born with congenital malformations. Ann Genet 2003, 46:1-5.

45. Carroll SG, Kuo PY, Kyle PM, Soothill PW: Fetal protein loss in gastroschisis as an explanation of associated morbidity. Am J Obstet Gynecol 2001, 184:1297-1301.

\section{Pre-publication history}

The pre-publication history for this paper can be accessed here: http://www.biomedcentral.com/1471-2431/11/90/prepub

doi:10.1186/1471-2431-11-90

Cite this article as: Payne et al:: Growth restriction in gastroschisis: quantification of its severity and exploration of a placental cause. BMC Pediatrics 2011 11:90.

\section{Submit your next manuscript to BioMed Central and take full advantage of:}

- Convenient online submission

- Thorough peer review

- No space constraints or color figure charges

- Immediate publication on acceptance

- Inclusion in PubMed, CAS, Scopus and Google Scholar

- Research which is freely available for redistribution

Submit your manuscript at www.biomedcentral.com/submit
C Biomed Central 